\title{
Small-scale characterization of vine plant root water uptake via 3-D electrical resistivity tomography and mise-à-la-masse method
}

\author{
Benjamin Mary ${ }^{1}$, Luca Peruzzo ${ }^{2,3}$, Jacopo Boaga ${ }^{1}$, Myriam Schmutz $^{3}$, Yuxin Wu ${ }^{4}$, Susan S. Hubbard ${ }^{4}$, and \\ Giorgio Cassiani $^{1}$ \\ ${ }^{1}$ Dipartimento di Geoscienze, Università degli Studi di Padova, Via G. Gradenigo, 6-35131 Padova, Italy \\ ${ }^{2}$ GO-Energy, Geosciences Division at Lawrence Berkeley National Laboratory, \\ Building 74, Calvin Road, Berkeley, CA, USA \\ ${ }^{3}$ EA G\&E 4592, Bordeaux INP, University Bordeaux Montaigne, Pessac, France \\ ${ }^{4}$ Earth and Environmental Sciences, Lawrence Berkeley National Laboratory, Berkeley, CA 94720, USA
}

Correspondence: Benjamin Mary (benjamin.mary@unipd.it)

Received: 1 May 2018 - Discussion started: 21 June 2018

Revised: 29 September 2018 - Accepted: 4 October 2018 - Published: 23 October 2018

\begin{abstract}
The investigation of plant roots is inherently difficult and often neglected. Being out of sight, roots are often out of mind. Nevertheless, roots play a key role in the exchange of mass and energy between soil and the atmosphere, in addition to the many practical applications in agriculture. In this paper, we propose a method for roots imaging based on the joint use of two electrical noninvasive methods: electrical resistivity tomography (ERT) and mise-à-la-masse (MALM). The approach is based on the key assumption that the plant root system acts as an electrically conductive body, so that injecting electrical current into the plant stem will ultimately result in the injection of current into the subsoil through the root system, and particularly through the root terminations via hair roots. Evidence from field data, showing that voltage distribution is very different whether current is injected into the tree stem or in the ground, strongly supports this hypothesis. The proposed procedure involves a stepwise inversion of both ERT and MALM data that ultimately leads to the identification of electrical resistivity (ER) distribution and of the current injection root distribution in the threedimensional soil space. This, in turn, is a proxy to the active (hair) root density in the ground. We tested the proposed procedure on synthetic data and, more importantly, on field data collected in a vineyard, where the estimated depth of the root zone proved to be in agreement with literature on similar crops. The proposed noninvasive approach is a step forward towards a better quantification of root structure and functioning.
\end{abstract}

\section{Introduction}

\subsection{Problem statement}

Soil root systems play a pivotal role in the many soil hydrological functions. Soil-plant interactions are complex, time dependent, scale dependent, species dependent and spatially heterogeneous. Special attention shall be paid to plant roots. It is therefore important to have techniques allowing us to assess root system properties at the appropriate support scale.

\subsection{Noninvasive measurements and electrical properties of the root system}

Noninvasive methods can provide spatially extensive, highresolution information that, supported by traditional local data, helps complete the complex picture of subsoil structure and dynamics. Among noninvasive methods, Grote et al. (2010) discussed the use of the ground-penetrating radar (GPR) for water estimation in a vineyard. However, the scope of the investigation of GPR is often limited by the soil type and is difficult to apply in clayed soil, and resolution is constrained by available wavelengths. A more developed approach is electrical resistivity imaging (ERI) - also called electrical resistivity tomography (ERT) - which can be particularly informative regarding soil water content. In most soil types, electrical resistivity (ER) can be described as a function of porosity, saturation of electrolyte, its $\mathrm{pH}$ and mineralization within the pores (Archie, 1942), clay con- 
tent (and generalized Archie's laws) and temperature (e.g., Campbell et al., 1949). Water content could be derived from the measured ER using pedotransfer functions such as the well-known Archie's law or other approaches (e.g., Rhoades et al., 1976; Waxman and Smits, 1968). Since absolute soil moisture content is of limited interest for researchers and professionals which are focused on the soil water availability for the plant, several studies relate the application of the variation of ERT or the fraction of electrical resistivity variation (FERV) introduced by Brillante et al. (2016) as a predictor of the fraction of transpirable soil water (FTSW) and related variables.

Amato et al. (2008) tested the capability of 3-D ERT to quantify root biomass on herbaceous plants using resistivity root correlation and calibration. Electrical methods have been also used to identify root water uptake (RWU - e.g., Cassiani et al., 2012; Garré et al., 2011; Michot et al., 2003; Srayeddin and Doussan, 2009) and demonstrated the match between soil water content variations and temporal changes in electrical resistivity. Cassiani et al. (2016) monitored the electrical resistivity in an apple orchard under external forcing conditions (irrigation- and plant-driven evaporation) and showed that the increase in resistivity is located in the subsoil region where active roots are present. Electrical and electromagnetic methods have been also used to identify root water uptake (e.g., Cassiani et al., 2015). Werban et al. (2008) performed an interesting ERT study on lupine roots and showed that rooted soil differs from bare soil in terms of the pedophysical model. Several studies related to soil-root systems have shown that the measured root mass density statistically correlates with the electrical conductivity (EC) data obtained from ERT (Amato et al., 2008). Nevertheless, in some cases, the ranges of electrical resistivity of soil and roots overlap. The amplitude of contrasts varies according to the soil resistivity and tree species (Zanetti et al., 2011; Mary et al., 2016), to the water content and the decay state of the wood itself (Martin, 2012), and to variations in soil water content (Garré et al., 2011; Beff et al., 2013; Cassiani et al., 2015; Mary et al., 2016). The problem would complicate further the correlation with root mass considering heterogeneous soil properties and moisture, as well as the electrical anisotropy caused by the root system, i.e., the root connectivity and root structure as further described in Rao et al. (2018).

Recent studies have shown a correlation between bulk electrical resistivity and root mass density, but an understanding of the contribution of the segments of the root system (by its own properties, with no interaction with soil) to that bulk signal is limited to only a few studies describing wood electrical properties. Gora et al. (2015) reviewed the literature describing electrical properties of stems noting large differences between trees and vine plants' resistivity values (200\% higher for trees), suggesting that there is a phylogenetic basis for variation of the ER that reflects the influence of anatomy and physiology. Observations from stems are directly transposable to roots. The range of electrical resistivity of roots depends on their nature. Typically, coarse roots, because of the heartwood and the isolative layer of bark, are considerably more resistive than fine roots (Hagrey, 2007). Electrical resistivity is also linked to the physiological state of the roots. Depending on the season, roots carry electrical charges as sap composition is variable and sap flows vary in intensity and direction. Wood composition and physical properties also change with root decay, which implies a variation of electrical properties (Martin, 2012; Martin and Günther, 2013; Weller et al., 2006). Very recently, Rao et al. (2018) produced an interesting study aiming at understanding bulk electrical conductivity on individual root segments, incorporating the impact of roots in the pedophysical relations to better infer the real soil water content.

Finally, root water uptake and the release of different exudates by fine roots change soil water content and resistivity at several temporal scales (York et al., 2016): on a daily basis (night vs. day, sunny vs. cloudy days) and seasonally (growth period vs. winter or drought season). In conclusion, roots might have a considerable impact on ERT signals, but this may not be directly measurable: ERT thus is an indirect determination of root presence.

Other bioelectrical phenomena can contribute to a more effective characterization of root properties. Plant water uptake generates a water circulation and a mineral segregation at the soil-roots interface, thus inducing an ionic concentration gradient which generates an electrical potential of a few $\mathrm{mV}$. This can be measured in terms of a passive distribution of voltage in the soil (Boleve, 2009). Gora et al. (2017) provide a framework for studying the ecological effects of lightning in the context of electrical properties of trees. Also, Gibert et al. (2006) and Le Mouël et al. (2010) measured natural variations of electrical potential using electrodes in the stem. They respectively measured $25 \mathrm{mV}$ due to daily variations of sap flow and 10 to $50 \mathrm{mV}$ caused by the flow of thunderstorms, which would produce soil charges and give rise to a current circulating through the roots and the tree stem. In theory, by analyzing the voltage distribution in the soil, it is possible to find the characteristics of the sources (depth and extension) causing the voltage anomaly (Saracco et al., 2004). In practice, these sources are too low in generally noisy environments. But one may think about taking advantage of these results to build an active method producing current flow and potential distribution into the soil.

\subsection{The mise-à-la-masse method applied to plant root systems}

In this study, we aim at investigating the feasibility of the mise-à-la-masse (MALM) method in the context of plant root mapping. MALM is an electrical resistivity method originally developed to delineate conductive ore bodies for mining exploration purposes (e.g., Schlumberger, 1920; Parasnis, 1967). An electrical current is injected into a conductive body and the resulting voltage values are measured at the 
ground surface or in boreholes; the shape of equipotential contour lines is informative about the extent and orientation of the conductive body in the subsoil.

In the plant stem and roots, electrical current is transmitted through active electrical layers, in the xylem and phloem (on either side of the cambium), where sap flow processes take place. Our main assumption is to consider that, thanks to the quasi-infinite fine root connections and their mycorrhiza at the interface between roots and soil, current tends to run out uniformly from the roots to the soil. In the context of MALM applications, the tree root system can thus be viewed as the conductive body to be imaged, with some important caveats: current may be carried within the roots but is likely to be released into the soil only at the points where fine roots emerge from the woody root structure. As fine roots are the active ones, this would be of major interest for the plant science community. Note that this is not necessarily proven for non-woody plant species. For instance, Anderson and Higinbotham (1976) showed that maize roots have significantly lower electrical resistance in the radial compared to the axial direction (thus being anisotropic), thus allowing current to exit laterally from the entire root length.

In practice, for MALM applied to root prospection, the current is to be injected directly into the tree stem with one electrode, while the other current electrode is placed in the soil at some distance from the tree. Voltage is measured at the soil surface and in boreholes with respect to a second, remote reference voltage electrode.

It must be noted that soil and root conductivity depends, among other parameters, on seasonal variations, water content or even salinity of the soil, making the interpretation potentially complex. In contrast, the sensitivity of MALM to water content makes the monitoring of plant water uptake occurring near roots possible and strengthens interpretation of their location.

Some knowledge gaps exist concerning root electrical properties. However, several theories have been proposed in the scientific literature in this respect, all confirming that each root may act as a current source in the MALM configuration above:

- Dalton (1995) analyzed the root-soil circuit and proposed a conceptual model with an electrical analog composed of resistance $R$ and capacitance $C$ (the ability of a system to store an electric charge). In that model, the internal fluid (xylem and phloem) of the plant roots constitutes a duct of low resistance which is separated from a low-resistance external medium (soil) by insulating root membranes (Ozier-Lafontaine et al., 2005). These membranes, in addition to being insulating, accumulate charges on the surface. Observation from Dalton and subsequent theories are fully consistent with the use of MALM for plants, even though the capacitance part is not exploited in these measurements. A bench- marking of the experimental approaches supporting the subsequent theories is proposed in Postic et al. (2016).

- The second theory is based on the notion of absorbing root surface and developed in the studies of Aubrecht et al. (2006) and Cermak et al. (2006). These studies indicate that if a plant growing on soil is connected to a simple serial electric circuit, then current flowing through this circuit from the external source enters the plant entirely through the absorption zones (or vice versa). Electric current can also flow through impermeable walls of other cells, but with a negligible density.

- A third theory is based on root polarization of biomatter as a proxy of root current pathway. As previously mentioned, root systems are commonly modeled using an electrical circuit composed of resistance $R$ and capacitance $C$ within the Dalton (1995) and similar refined models (Aubrecht et al., 2006; Cermak et al., 2006). This means that the conduction of the current through the root system depends on current characteristics. For alternating currents (AC), the resistivity of a polarizing medium is a complex number, having a resistance and capacitance part, and is therefore dependent on frequency. This shift is dependent on some specific plant parameters, and its assessment could also contribute to better discriminating root and soil current conduction. Mary et al. (2017) considered polarization from soil to root tissues, as well as the polarization processes along and around roots, to explain the phase shift observed for different soil water content. Weigand et al. (2017) demonstrate that multi-frequency electrical impedance tomography is capable of imaging root system extent as well as monitoring changes associated with root physiological processes.

Given the review of current knowledge on electrical properties of roots, in this paper we hypothesize that the mise-àla-masse method can be a viable tool to locate active roots under in situ conditions. The paper has the following aims:

1. define a viable field protocol that uses jointly MALM and ERT to map active tree vine roots,

2. propose and analyze algorithms capable of identifying the location of active roots, and

3. test the algorithms above against real data from a French vineyard.

A discussion of the results will be provided in light of biological assumptions. 


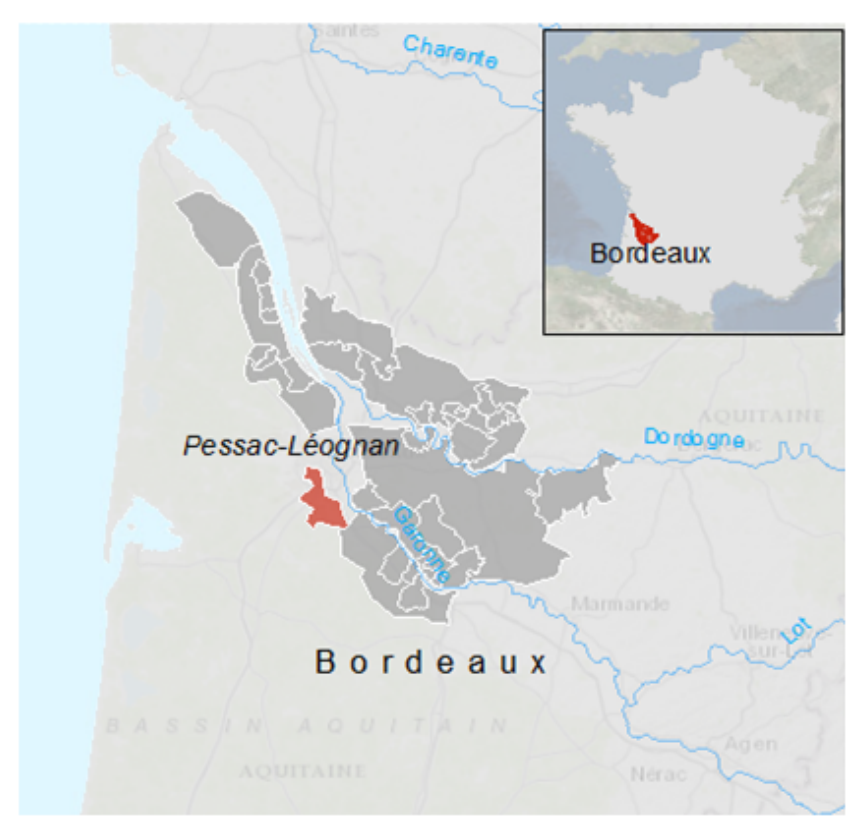

Figure 1. Location of the experimental site in Bordeaux (France).

\section{Materials and methods}

\subsection{Site description}

The field study was carried out in a vinery of the Château La Louvière appellation contrôlée, located in Pessac-Léognan (Fig. 1a) near Bordeaux (Gironde, France). The climate of the region is oceanic with an average annual air temperature of $13.7^{\circ} \mathrm{C}$ and total annual rainfall of $811 \mathrm{~mm}$ (André et al., 2012). According to the meteorological station near the experimental plot $(200 \mathrm{~m})$, the study period was wet after rainfall, with an air temperature of $11^{\circ} \mathrm{C}$. The topography of the plot is mostly convex with an average slope of about $10 \%$ but less than this value at the location of the experimental plot, thus inducing small surface water runoff.

\subsubsection{Soil characteristics and prior knowledge on root systems}

Despite heterogeneities of soil types composing the vineyards (André et al., 2012), the plot is located in a similar soil system (Baize and Girard, 1995). Moreover, the organization of the soil sequence and root density was investigated with observation trenches. The closest one to the experimental plot shows an organization, with a first sandy horizon $(0-40 \mathrm{~cm}$ depth), porous and soft. Rooting depth has been qualitatively observed on a bare soil at the emplacement of uprooted vine plants and can only be seen as ancillary information. In this horizon, all root sizes with a rather horizontal and oblique orientation were observed. The second layer (40-105 cm depth) is identical to the top layer in terms of soil composition, but contains less roots. A third layer (deeper than $105 \mathrm{~cm}$ ) is relatively similar to the previous ones with only very few fine roots. From 125 to $175 \mathrm{~cm}$ depth the soil type changes to sandy-clayey. The described geology, morphology and microclimate of the regional context defines the so-called terroir de grave of this vineyard, where vine plant species have been planted. For this study, we selected an apparently healthy plant. Considering the soil composition, the vine water supply is facilitated thanks to the possible capillary rise from the sandy-clayey horizon which retains sufficient water for vine use and generally contains sufficient nutrients for vine growth. Grapevine plants are planted with a distance of $1 \mathrm{~m}$ between plants and $1.5 \mathrm{~m}$ between rows. The vineyard is non-irrigated. Considering also the selected plant and the slight slope of the vineyard, it might be reasonable to foresee a top layer rooting with an asymmetric development (gravitropism).

\subsection{The 3-D scheme of ERT and MALM setup acquisition and processing}

The 3-D ERT setup was originally developed by Boaga et al. (2013) and subsequently improved and adapted at different sites to obtain successful results regarding soil-plant interactions, for example, in salt marsh environments (Boaga et al., 2014) and in apple and orange orchards (Cassiani et al., 2015, 2016; Consoli et al., 2017; Vanella et al., 2018). The apparatus was adapted again and applied for the first time in a vineyard for this study. Figure 2 shows the geometry of the electrode system: four micro-boreholes define a rectangular domain, $1 \mathrm{~m}$ along the vineyard direction $(y)$ and $1.2 \mathrm{~m}$ in the perpendicular direction. Each borehole houses 12 electrodes with $0.1 \mathrm{~m}$ vertical spacing. In addition, 24 surface electrodes define a regular grid. Such disposition allowed us to conduct high-resolution measurements around the selected vine plant (Fig. 2). Field measurements were conducted in March 2017, using a 10-channel resistivity meter (Syscal Pro Switch 72, IRIS Instruments). For the 3-D scheme of ERT, a complete skip-two dipole-dipole scheme was adopted and produced some 5000 measurements, including reciprocal measurements used to estimate and reject bad data quality (Binley et al., 1995; Daily et al., 2004). A pulse duration of $250 \mathrm{~ms}$ for each measurement cycle and a target of $50 \mathrm{mV}$ for potential readings were set as criteria for the current injection. The R3t code (Binley, 2013) was used for data inversion.

\subsection{MALM acquisition, modeling and processing}

\subsubsection{MALM acquisition and forward modeling}

The MALM acquisition used the same electrode arrangement as described above, with only a couple of necessary changes: the two remote electrodes for current $(B)$ and potential $(M)$ see Fig. 2 - were located at a large ("infinite") distance, more than 20 times the maximum distance between the other elec- 


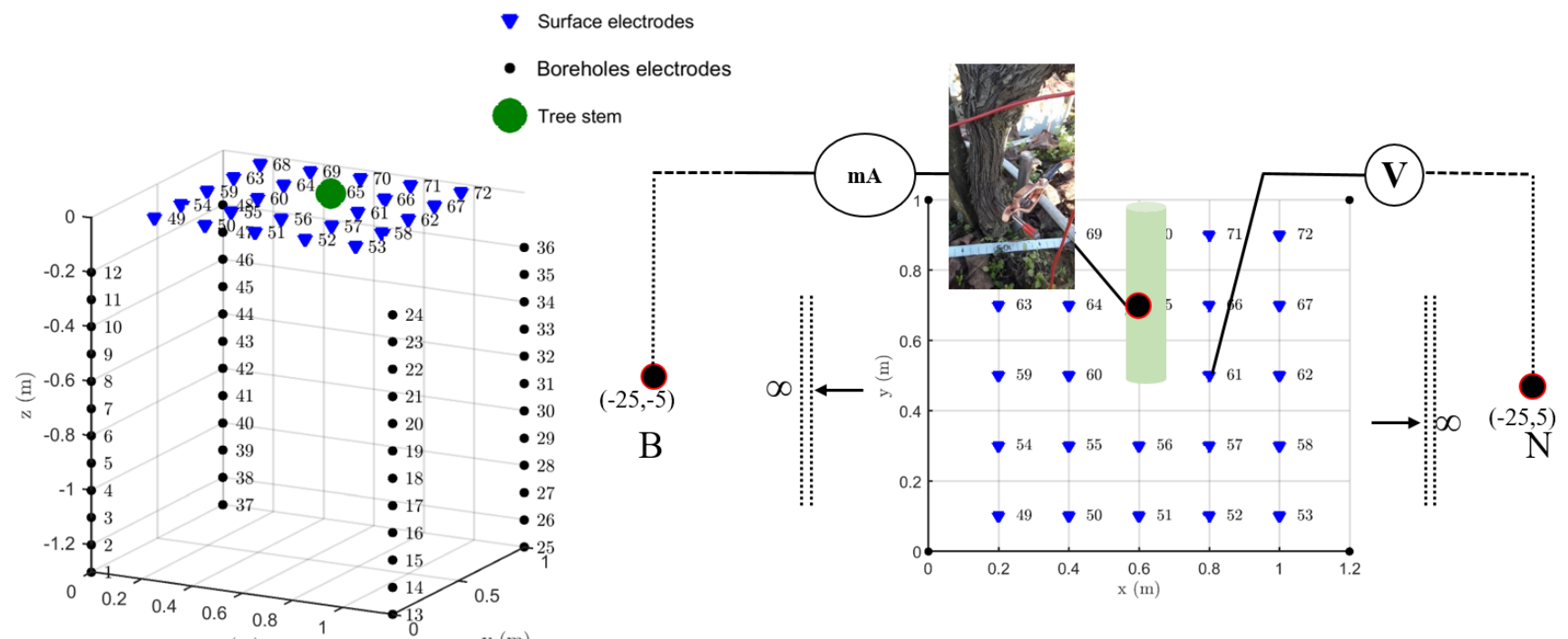

(a)

(b)

Figure 2. The 3-D schemes of electrical resistivity tomography (ERT) (a) and mise-à-la-masse (MALM) mesh (b); B and M are remote electrodes placed $25 \mathrm{~m}$ apart from the plot.

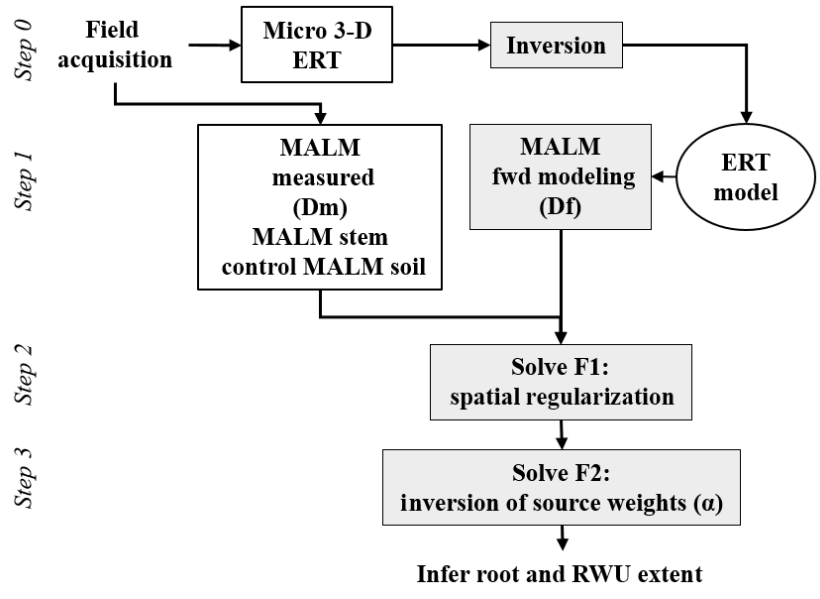

Figure 3. Flow chart of the analysis of MALM as described in this paper, from data acquisition, processing and interpretation in terms of RWU region identification.

trodes, as suggested by Robain et al. (1999). An additional electrode was placed near the stem (Fig. 2). Two different datasets were acquired depending on the position of the current injection electrode $\mathrm{A}$, as described in the workflow in Fig. 3: (i) the first case was a real MALM acquisition where the injection electrode A was planted into the apparent conductor (i.e., the plant stem); (ii) the second case is a reference (or false MALM) case, with the injection electrode A planted in the soil very close to the stem. A comparison between the two acquisitions is expected to show the effect of the plant as a current conveyer. All surface and borehole remaining electrodes (69) are used to measure voltage. Compared to poledipole used for capacitive measurements with two electrodes implanted into the stem (Aubrecht et al., 2006; Cermak et al., 2006), there is no additive stem resistance to consider and this fact is particularly important for the data interpretation. However, good contact of the electrode with the stem must be ensured for the true MALM acquisition: the current electrode was planted about $1 \mathrm{~cm}$ into the $5 \mathrm{~cm}$ wide stem, thus reaching the cambium layer and ensuring a stable contact resistance of about $10 \mathrm{k} \Omega$. Reciprocal measurements were also acquired in MALM (Fig. A1 in the Appendix). In order to compare voltage data against simulations (see below), values of the potential measured on the surface of the ground and in depth with boreholes were systematically normalized by the amplitude of the injected current.

Synthetic MALM data were produced (in forward mode) using the R3t code (Binley, 2013) and the same unstructured tetrahedral mesh used for ERT inversion. The quality of the meshing was checked by the comparison between a uniform $100 \Omega \cdot \mathrm{m}$ forward modeling with the corresponding analytic solution (Fig. A2). Inverted resistivity from 3-D ERT acquisition was considered as a resistivity distribution needed for the MALM forward modeling.

\subsubsection{Processing and interpretation using objective functions}

In order to interpret the results of the MALM acquisitions, a quantitative inversion of the voltage data is needed. This requires (a) the forward simulation of voltage values given 
a certain current source distribution in the soil (equivalent to the locations were current reaches the soil emerging from the roots); and (b) the minimization of an objective function that defines the discrepancy between measured and predicted voltages, where the minimization variable is the location of the electrically active roots. Steps (a) and (b) are equivalent to inverting the data for the current source distribution in the soil, which in our conceptualization also represents the distribution of active (fine) roots in the system.

In the following, two different objective functions are introduced. First, assuming that a unique current punctual source is sufficient to fit the measured data, the following objective function is to be minimized:

$\mathrm{F} 1\left(D_{\mathrm{m}}, D_{\mathrm{f}, i}\right)=\left\|D_{\mathrm{m}}-D_{\mathrm{f}, i}\right\|_{2}$,

where $D_{\mathrm{m}}$ is the measured voltage $(\mathrm{V})$ and $D_{\mathrm{f}, i}$ the forward voltage data for one source positions ( $i$ th node of the mesh). The F1 function can help guide the search for the region where the presence of active source is most likely to concentrate, but of course the use of F1 alone does not represent a realistic distribution of sources in the MALM inversion.

A more realistic objective function, which takes into account the presence of distributed sources, has also been introduced:

$\mathrm{F} 2\left(\alpha_{i}, D_{\mathrm{m}}, D_{\mathrm{f}, i}\right)=\left\|D_{\mathrm{m}}-\sum_{i=1}^{\mathrm{Ns}} \alpha_{i} \times D_{\mathrm{f}}\right\|_{2}$,

where $0<\alpha_{i}<1$ expresses the contribution of source $i$, with the constraint $\sum_{i=1}^{\mathrm{Ns}} \alpha_{i}=1$, where Ns is the total number of current sources that ensures that the electrical charge (and thus the electrical current) is conserved. The number of current sources to invert for Ns is primarily dictated by the desired input mesh quality (Fig. A2c). This is determined by the required computational time. For this small-scale prospection, we adopted a mesh composed of 23700 nodes (including remote electrodes, e.g., Fig. A2a). The inversion region was limited to 3618 nodes (Fig. A2b). Furthermore, as shown in Fig. 3, the strategy is to use the F1 and F2 optimizations sequentially. In order to guide the physically sound F2 inversion, initial values of $\alpha_{\mathrm{io}}=\left[\alpha_{1 o}, \alpha_{2 o}, \ldots, \alpha_{\mathrm{Nso}}\right]$ were set using normalized F1 values (between 0 and 1 ). This is equivalent to applying a regularization based upon the initial F1 search upon the F2 optimization. A global optimization using a constrained nonlinear optimization algorithms method (fmincon solver using a gradient-based method associated with the sequential quadratic programming, SQP, optimization algorithm) implemented in MATLAB ${ }^{\circledR}$ (R2016b) software was then used to minimize F2.

\subsubsection{Testing of the inversion procedure: a synthetic data example}

In this synthetic example, we used the same configuration, mesh and protocols as for the real case (see Sect. 2.2). Figure 4 shows the initial model with the location of a cubic resistive anomaly $(500 \Omega \cdot \mathrm{m})$ embedded in a $100 \Omega \cdot \mathrm{m}$ background. The anomaly is slightly shifted compared to the acquisition domain. A dipole-dipole skip-two protocol was adopted for ERT acquisition (Fig. 3, step 0). The same mesh was used for ERT and MALM simulations.

The resistivity distribution obtained from ERT was used, as necessary in real cases, as the background resistivity through which the current, induced by the MALM experiment, flows. In this synthetic example, the MALM datasets (see Fig. 3 - ERT Model) are obtained hypothesizing current source locations (at the FE mesh nodes) within the given theoretical root zone - the current intensity is assumed the same at all nodes. Figure 4 shows the distribution of the voltage, solution of the sum of the contribution, measured with surface (Fig. 4c) and borehole electrodes (Fig. 4d). Results from F1 minimization allowed for a preliminary selection of the region where individual sources should be considered for weight distribution in F2 minimization. The minimum number of sources was selected according to the evolution of the curve of sorted misfit F1 (the same procedure applied to the real data, see Sect. 3): any increase in the number of candidate source locations does not significantly decrease the F1 value. In this synthetic case, a minimum misfit F1 reaches a value of $17 \%$, and the corresponding contours of the F1 objective function (Fig. 5a) indicate the volume of the true anomaly. This step results in the selection of probable sources defining a preferential search space area for the subsequent F2 minimization.

Source weight results inferred from F2 minimization (distributed weighted sources assumption) were then sum to compute an inverted model. Figure 5 shows the solution, the inverted model for the surface and borehole electrodes for the synthetic case. The asymmetric nature of the solution is clearly visible from both surface and borehole electrodes.

\section{Experimental results}

\subsection{Field 3-D ERT measured data}

Figure 6 shows the solution of the inversion from the 3-D ERT data acquisition. The pulse duration was $250 \mathrm{~ms}$ per measurement cycle, and the target voltage was $50 \mathrm{mV}$ for the current injection. The result of a measure corresponds to the mean of between three and six stacks with a relative difference between two stacks of $5 \%$ on the resistivity term. Contact resistances were good during the acquisition: by accepting a threshold equal to $5 \%$ for reciprocity error, only $12 \%$ of the measurements were rejected. Electrical resistiv- 

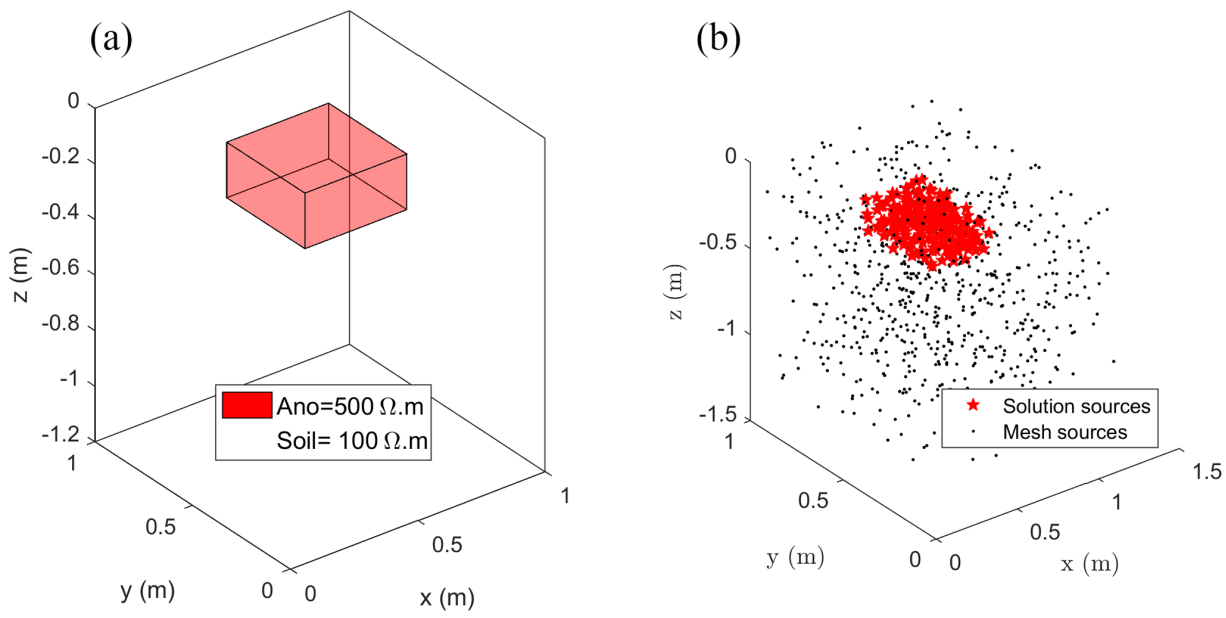

(c)

(d)
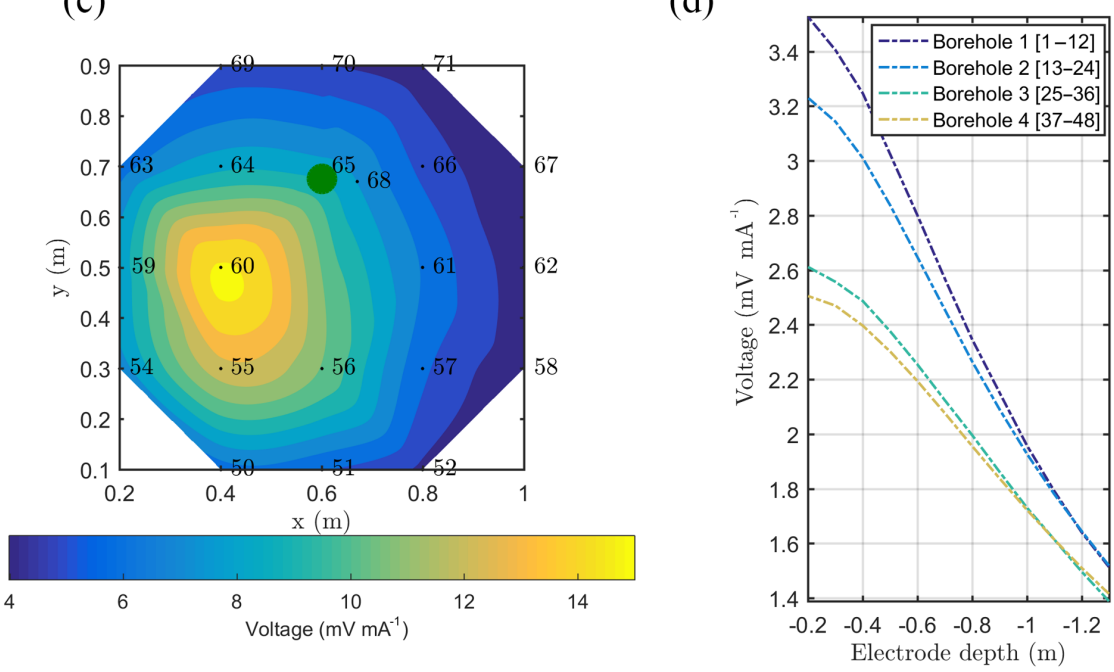

Figure 4. (a) Initial anomaly of $500 \Omega \cdot \mathrm{m}$ located in a domain of lower resistivity $(100 \Omega \cdot \mathrm{m})$; (b) black dots are all virtual sources tested during the inversion process, and red stars are sources forwarded to compute the solution; (c, d) solution of the sum of all sources' contribution on the surface and with borehole electrodes. The green point shows the positions of the plant stem.

ity ranges from 100 to $250 \Omega \cdot \mathrm{m}$ with significant lateral and vertical spatial variations (Fig. 6). Soil texture is expected to be rather homogeneous with depth, except at the very top where the soil tillage can induce also electrical resistivity changes. A profile taken at $0.2 \mathrm{~m}$ depth (Fig. 6a) shows two distinct peaks of resistivity, with the first peak corresponding to the highest value of ER $(250 \Omega \cdot \mathrm{m})$ located at $y=0.78 \mathrm{~m}$, close to the plant stem position but with some slight shift. In the 3-D visualization (Fig. 6c) the high-resistivity peak corresponds to an extended anomaly around the plant.

When considering the electrical resistivity profile with depth below the stem (Fig. 6b), a maximum region between 0.2 and $0.4 \mathrm{~m}$ depth is clearly visible. A horizontal profile at $0.4 \mathrm{~m}$ depth (Fig. 6a) confirms a maximum around $y=0.7 \mathrm{~m}$, which is not far from the stem location. At larger depths no noteworthy features are apparent since neither soil tillage nor plant roots seem to act on the electrical resistivity of the soil.

\subsection{MALM results}

As discussed above, we acquired direct and reciprocal measurements also for the MALM data. A comparison between direct and reciprocal resistances allows us to, in ERT, quantify the data quality, remove outliers and define the error level to be adopted in the data inversion procedure. However, the reciprocity theorem holds only in case of linearity (Parasnis, 1988). In the MALM case at hand, linearity may be violated when current is injected into the tree stem (by accepting a threshold equal to $5 \%$ for reciprocity error, only $10 \%$ of the measurements were rejected for the stem injection while $7 \%$ of the measurements were for the soil injection). And indeed 

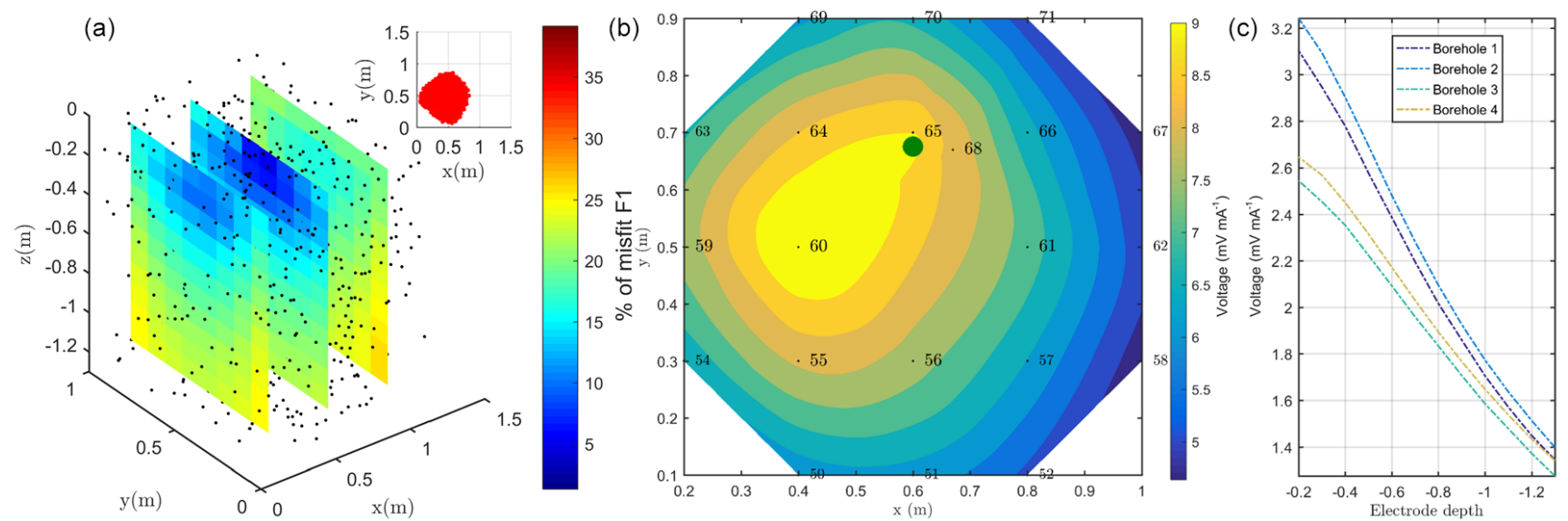

Figure 5. (a) Spatial distribution of F1: the black dots show the virtual source locations. In the top right corner, the selected sources (for a misfit of $17 \%$ ) inferred from the study of the cumulative sum of the misfit (or curvature); (b) inverted model obtained after sources ponderation considering the distributed function F2 for surface electrodes. The green point shows the positions of the plant stem (c) for borehole electrodes.
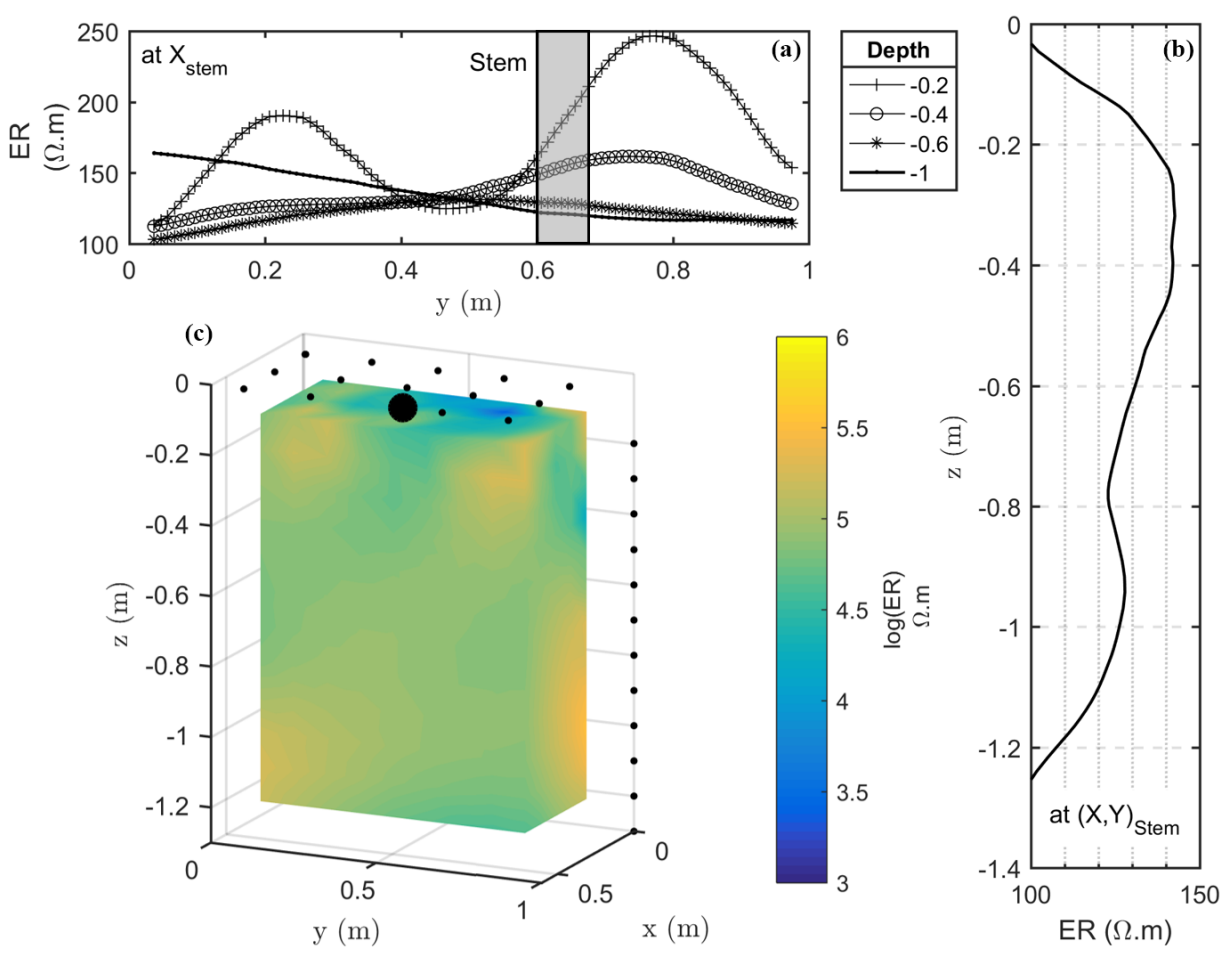

Figure 6. Results of the 3-D ERT inversion: (a) 2-D lateral ( $y$ direction) variations of resistivity at four depths $(0.2,0.4,0.6,1 \mathrm{~m})$; (b) 2 -D vertical variations of resistivity at the tree stem location; (c) 3-D resistivity volume (log scale) sliced at $x=0.5 \mathrm{~m}$, with the black point showing the location of the plant stem.

the differences between direct and reciprocal data (Fig. A1) seem to be systematic and linked to the region around the stem. In the following we will refer to the MALM results obtained by injecting current into the stem. Figure 7 shows a comparison between normalized voltage data obtained by injecting current into the stem and into the soil. At a very first glance, the spatial distributions of the voltage caused by stem and soil injection results appear very similar, with the striking exception of the voltage absolute values, with the stem injection leading to much lower normalized voltage values (maximum is $200 \mathrm{~V} / \mathrm{A}$ versus $500 \mathrm{~V} / \mathrm{A}$ for the soil injection) especially close to the stem. This is an indication that cur- 
(a)

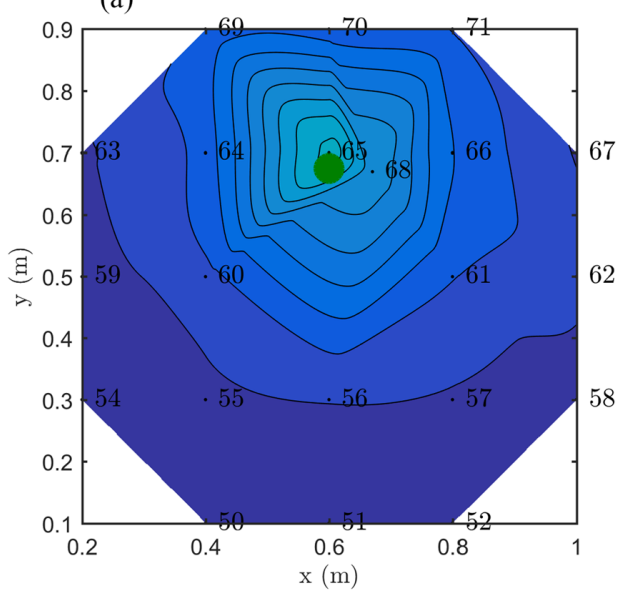

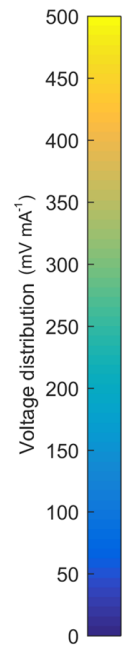

(b)

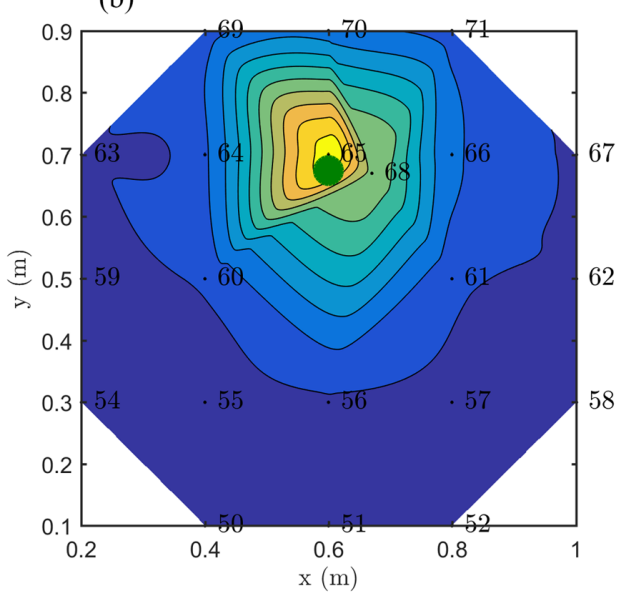

(c)

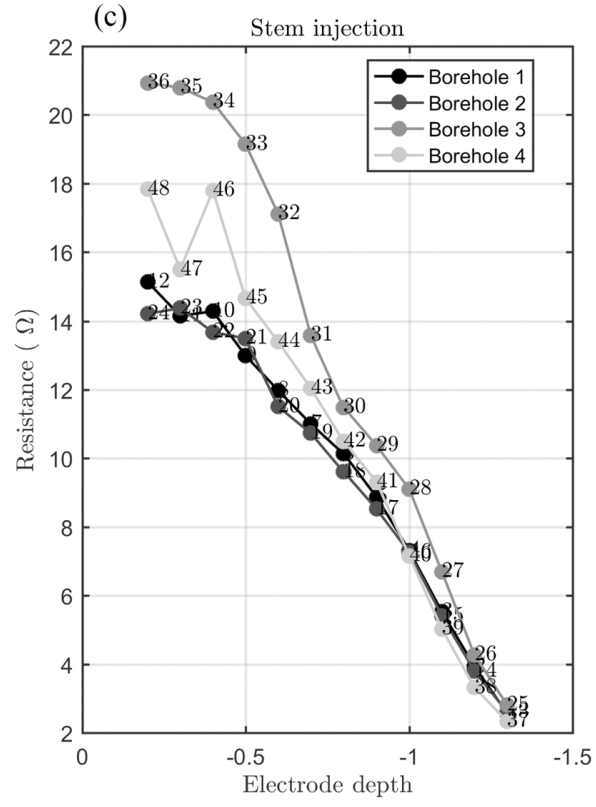

(d)

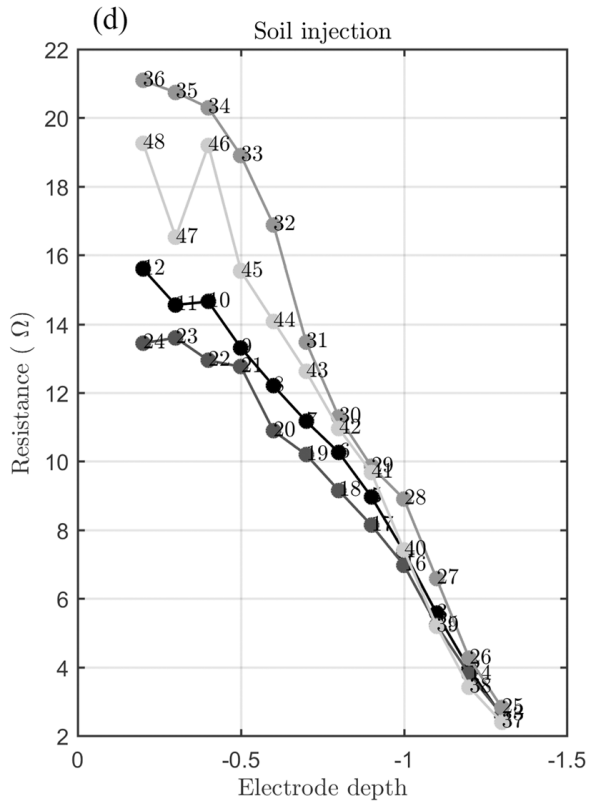

Figure 7. MALM acquisitions: spatial variations of the normalized voltage (in V/A) observed at surface and borehole electrodes. A comparison is shown between MALM voltage distributions when the current is injected into the soil (b, d) and into the stem (a, c). The green points show the positions of the plant stem.

rent is indeed not injected at the ground surface, but emerges at some point(s) below ground. Note that also the gradients along the ground surface are much steeper for the soil injection than for the stem injection, confirming the hypothesis just presented.

Figure 7 also shows borehole results, which appear to be more complex and harder to interpret in terms of actual current distribution. Normalized voltages range between roughly $20 \mathrm{~V} / \mathrm{A}$ at $0.1 \mathrm{~m}$ depth to nearly zero at $1.3 \mathrm{~m}$ depth. For both stem and soil injections, the voltage decreases regularly from 0.6 to $1.3 \mathrm{~m}$. Slight differences in the decay slope and between boreholes are only visible for the shallow region
$(0-0.6 \mathrm{~m}$ depth). In particular, in the presence of stem injection, the voltage is nearly constant from 0 to $0.3 \mathrm{~m}$ depth, while for soil injection the slope is slightly larger. This pattern is observed in each borehole. Borehole 4 shows some irregular behavior (one electrode is abnormally low, possibly because of bad contact with the soil. On average, voltages resulting from soil injection are higher than from stem injection. 
(a)
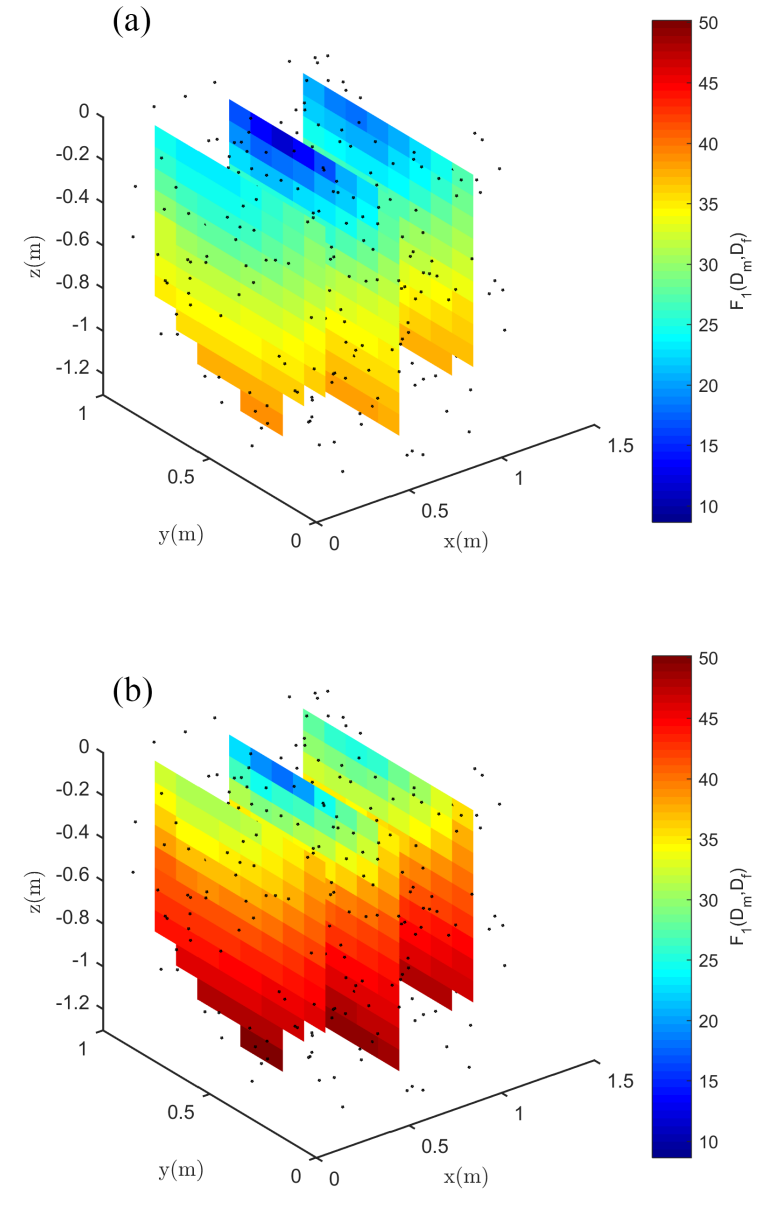

(c)

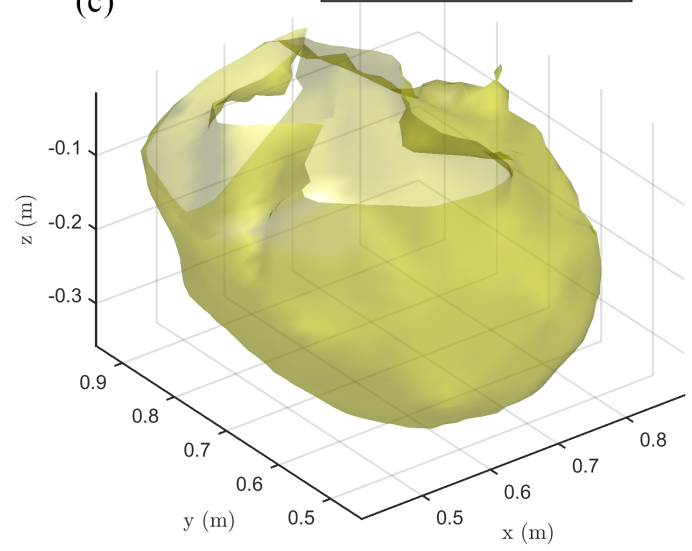

Figure 8. Spatial distribution of the F1 misfit function (e.g., Eq. 1) computed against field data and using the ERT-derived electrical resistivity distribution. (a) shows the case with stem injection, (b) the case with soil injection and (c) the contour surface of F1 $=17 \mathrm{~V}$ in the stem injection case for which only locations that would contribute in a substantial manner to reducing the F1 misfit are used.

\subsection{Inversion of MALM field data: punctual source search (F1 function)}

Figure 8 shows the spatial distribution of the F1 function, where the spatial dependence is implicitly accounted for by the index $i$ ( $i$ th node in the mesh) in Eq. (1). Each individual source was forwarded to produce a tentative normalized voltage at electrodes also as a function of the resistivity distribution reconstructed by ERT inversion of field data. Obviously, Fig. 8 shows that none of the single source positions is capable of fitting all data perfectly - the misfit range reproduced by F1 values in Fig. 8 is between $10 \%$ and $50 \%$. Nevertheless, the fit is not too low, and the F1 spatial distribution is a clear indication of the regions where distributed sources shall be placed to reproduce field data. For both injection schemes, in stem and soil, F1 values decrease with depth, but with different rates. In the case of injection into the soil, the source locations with a $20 \%$ misfit are very close to the ground surface (within $0.05 \mathrm{~m}$ depth). In the case of stem current injection, the same misfit level extends to a $0.3 \mathrm{~m}$ depth (Fig. 8c).

\subsection{Inversion of MALM field data: distributed sources (F2 function)}

Considering a single punctual source is, of course, a very rough approach in trying to identify the distribution of current sources that generate the observed MALM voltage distributions. Thus, we used the results of the section above only as a first approach to guide the identification of distributed current sources. The objective function in Eq. (2) - named F2 - was used for inversion of sources during stem current injection. Function F2 reflects the L2-norm (least squares) of the differences between the measured data and the sum of the sources weighted by a coefficient $\alpha$ that is accounting for the fraction of total current pertaining to that source. The vector of $\alpha$ values is the target of the inversion, while the locations of candidate sources are defined by the nodes of the finite element mesh used for forward modeling. Given the very large number of nodes, most of which are located in regions that are very unlikely to host active roots, and thus MALM current sources, we constrained the candidate locations on the basis of the results of the F1 inversion (see section above): only locations that would contribute in a substantial manner to reducing the $\mathrm{F} 1$ misfit (to $17 \%$ ) are used as candidate locations in the F2 minimization - about 200 locations were used (see Fig. 8c). The corresponding values of optimized F1 are used, after their sum is normalized to 1 , as initial guesses for $\alpha$ values to start the inversion. Individual $\alpha$ values are allowed to vary in the $1 \times 10^{-4}$ to 0.1 range. Current conservation was respected since the sum of the weight was equal to 1 at the end of the inversion iterations.

The result of the F2 minimization is shown in Fig. 9, where it is apparent how the region where distributed current sources are located is no deeper than about $0.3 \mathrm{~m}$ and 


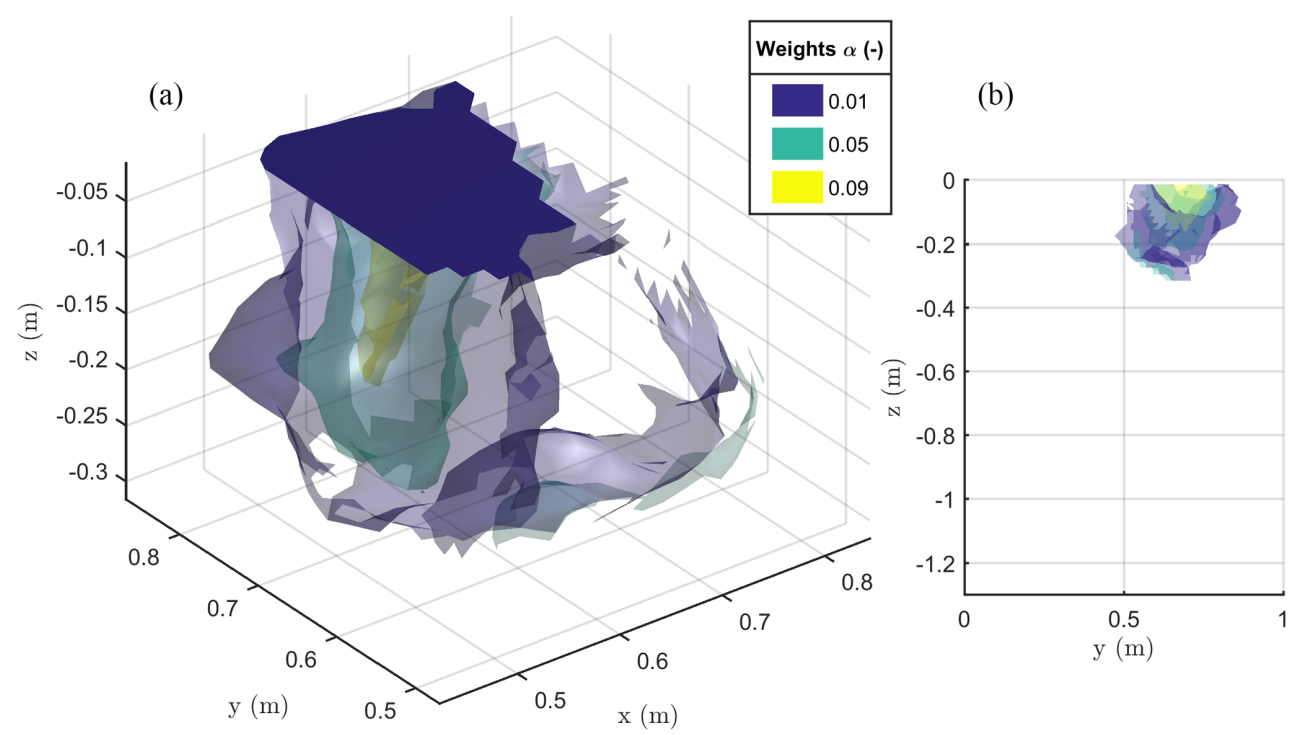

Figure 9. The 3-D view (a) and 2-D Y-Z view (b) of the iso-surfaces of current source contribution $\alpha$ after minimization of the objective function F2 as defined in Eq. (2). The results are relevant to the stem current injection.

has a lateral extent between 0.5 and $0.9 \mathrm{~m}$. This is likely to be the extent of the plant active roots.

\section{Discussion}

This study shows how the joint use of ERT and MALM can help the characterization of a plant root system. However, while we show how substantial progresses can be made, it is apparent that a number of tricky details must be considered and further developments are needed. Our work clearly shows that the MALM method can provide key information concerning the root system spatial distribution of woody species (with the latter discussed uncertainties). This is apparent from the simple comparison of (normalized) voltage distribution as produced by current injection into the soil and into the plant stem (e.g., Fig. 7). However, the differences in normalized voltage between stem and soil current injection, even though apparent, are not such as to evidently point towards a self-evident distribution of current sources to be associated in an obvious manner to an active root distribution. Thus, we must go beyond a simple qualitative approach.

Modeling has been used recently to bridge the gap between simple voltage measurements (MALM) and complex three-dimensional inverse modeling (ERT). The gap is caused essentially by the relative scarcity of data inherently linked to the MALM acquisition as compared to the wealth of data generally acquired in ERT (and especially in 3-D ERT) acquisitions. Recent examples are given, for example, by De Carlo et al. (2013) and Perri et al. (2018). In all cases, forward modeling of MALM is used to compare simulated and measured data, given certain assumptions concerning, usually, the distribution of electrical resistivity in the subsurface
- since injected current locations are known. In the present case, we exploited modeling in a different manner, taking full advantage of the joint availability of MALM and ERT data on the same configuration. As in other MALM studies, the modeling exercise is used to test some underlying assumptions: in this case, we assume that injecting current into the plant stem causes a distribution of electrical current sources in the ground that corresponds to the locations of active roots, i.e., to the locations where roots are in contact with the ground also in terms of electrical conductance. The fact that this contact does not correspond to the place where the plant stem touches the ground is verified by the simple comparison between stem and soil injection - which produce different MALM voltage distributions. The modeling exercise is actually set up as an inversion process, as in our case we only aim at identifying current injection locations, as the electrical resistivity distribution is assumed to be known from the independently acquired 3-D ERT results. In practice, a double inversion is carried out: (1) ERT data are inverted to give the estimated electrical resistivity distribution; (2) assuming that the ERT-derived resistivity is correct, stem injection MALM data are inverted only for the locations of current sources.

The procedure above is not free from uncertainty, particularly when it comes to the following:

- The identification of current source locations is inherently an ill-posed problem, as the number of candidate locations is potentially very large and the current intensity for each injection point is of course unknown. Given that the MALM normalized voltage is only measured at a very limited number of electrodes, we cannot expect that a unique solution is possible. However, the space of possible solutions can be constrained and volumes of 
likely current injections can be identified, as we demonstrate both in the synthetic and real cases above.

- The electrical resistivity distribution in the ground has a strong impact on measured MALM voltages. In this respect we can only trust the effectiveness of ERT in identifying this distribution, at least within the precision needed for its use in MALM source inversion.

The two points above have the consequence that the overall minimization of objective functions F1 (e.g., Eq. 1) and F2 (e.g., Eq. 2) cannot lead to very small misfit values, especially if the possible distribution of sources for F2 is constrained a priori by the F1 distribution. We accept that the resulting misfit is a measure of the limitations inherent in the assumptions made.

The main assumption that is made is that the root system acts as a preferential electrical pathway, with current flowing inside the conductive parts of the roots (xylem and phloem), and thus preventing the release of the current from roots to soil across the roots' woody outer bark. The current is ultimately discharged to the soil by the multitude of thin/hair roots. In practice, more research should be conducted in order to establish whether the current is going through the entire root system and how the vast number of hair roots contribute to the release of current. Water acquisition and by extension the electrical current pathway are thought to be limited to the surface located close to the root tips. At least two other phenomena may contribute to current release that is higher than expected. Firstly, Cuneo et al. (2018) show that, although woody portions of roots act as an electrical barrier (also to microbial degradation), exchanges may occur during water uptake (in order to facilitate localized embolism repair in grapevines). Secondly, as discussed also in the introduction, some roots show anisotropic electrical conductivity, allowing current to flow radially more easily than longitudinally (Anderson and Higinbotham, 1976). In this case, our proposed MALM approach would need to be modified in the interpretation stage. Note that roots are generally electrically anisotropic at the microscopic scale (few $\mathrm{cm}$ ) and also macroscopically the root architecture and soil water uptake pattern can induce anisotropy. Using MALM to study the anisotropy of root structures can indeed be a separate, very promising area of research. Note that the presence of electrical signals, such as action potentials (AP), in plant cells suggested that ion channels may transmit information over long distances (Pyatygin et al., 2008).

The results of our field study, albeit within the uncertainties just described, identify the presence of current sources, and thus likely the root system, within the top $30-40 \mathrm{~cm}$ depth. This is not totally unexpected, even though we observe a slightly shallower range than usually reported in the literature dealing with wine root systems (Stevens and Douglas, 1994; Gerós et al., 2015). Moreover, roots with a diameter ranging from 0.5 to $2 \mathrm{~mm}$, which have water and nutrient foraging and uptake functions (Herralde et al., 2010), represented the majority of the total, on average more than $80 \%$ in most studies, of grapevine cultivars (Swanepoel and Southey, 1989; Morlat and Jacquet, 2003; Nagarajah, 1987). This is in agreement with our assumption that a vast number of small current sources correspond to the root distribution. Finally, it is well known that fine, medium and woody roots are not adequately distributed with depth and the number and the diameters of the roots show a drastic decline with depth (Morano and Kliewer, 1994; Morlat and Jacquet, 2003; Tomasi et al., 2015). Our results are in clear agreement with this pattern that is mirrored by the decrease in $\alpha$ with depth. Although the rooting depth obtained in our study reaches approximately $0.3-0.4 \mathrm{~m}$ below ground, there are probably still roots growing below this depth. Their contribution to the MALM data is too low to be detected above the thresholds we applied for inversion, indicating a very small root density and the resolution limit of the MALM method. From this observation, one can consider a correction during the inversion process using a depth-weighting matrix. If the rooting depth increases, the acquisition may take advantage of the boreholes, preventing the loss of too much resolution. We previously discussed potential sources of errors as we lack a convincing ground truth for individual root segments due to the inadequacy of existing direct investigation methods. Indeed, excavation (e.g., via air spade), although very performant for container-grown plants, is only a good way of showing the large roots, but not their functioning in the field. Showing the woody roots is, for the most part, providing information on the structural support of the tree while RWU is controlled by fine structures that are in connection with the woody roots, but do not necessarily coincide totally with them. Already Dittmer (1937) reports that living root hairs (Secale cereale L.) may be scattered over the entire surface of all the roots; nevertheless, their relative number and length varied within the different root categories, and the smallest but most numerous were found in the quaternary division. Judd et al. (2015) reviewed the most frequently used field methods to measure or to analyze root systems and report that hair roots are destroyed during the field excavation using trench, window (Böhm, 1979), pinboards and monoliths techniques. Furthermore, these methods are static. As for the air spade, it has been widely used, but can even damage the coarse roots (Stokes et al., 2002). Existing less destructive methods such as auger core or (mini/meso)rhizotron can show aberrant root growth along the walls or windows and requires a large number of samples or tubes (Taylor et al., 1990), and of course these methods are not applicable in the field.

A number of applications that would benefit from knowing the location and activity of roots may emerge from our proposed approach. Among others, the refinement of allometric root-shoot factors to study competition between plants, the improvement of models for estimation of water available for plants (such as the FERV introduced by Brillante et al., 2016, as a predictor of FTSW) and the refinement of water balance 
modeling by assimilation of geophysical data (e.g., Manoli et al., 2015; Rossi et al., 2015). One issue that has not been addressed in this study is how roots conduct electrical current depending on the plant physiological state. Seasonal variations would significantly affect the ion content and intensity of sap flow. During the experiment in March the plant probably develops new roots and leaves (lateral shoot growth). The study period was wet after rainfall, with an air temperature of $11^{\circ} \mathrm{C}$. Conditions of the experiments were not optimized to fully highlight the root system. Limited water uptake was occurring during the experiment since the plant was not stressed. Sap flow was probably reduced, and so the resistivity of living plant tissues may have increased. Considering phenological phases of the plant may significantly improve the efficiency of the MALM approach we describe. A possible improvement would consist in using MALM to monitor an irrigation experiment or processes occurring after a rainfall event.

\section{Conclusions}

In this paper we present evidence showing how the joint use of MALM and ERT in a high-resolution, 3-D configuration around a tree (in this case a vine) can provide very detailed information about the plant root system. The results are based upon the hypothesis that current injected into the tree stem is conveyed through the root system and released in the ground at the locations where hair roots are in electrical contact with the soil. This hypothesis is fully supported by existing scientific literature. In addition, our experiments show that the injection into the stem produces a very different voltage distribution than the injection directly into the soil at the base of the stem: this is solid evidence that the plant structure redistributes current in the soil, and this can only happen through the root system.

In order to produce quantitative results concerning the root system structure, we adopt a three-step inversion process:

1. a 3-D ERT inversion provides the spatial distribution of electrical resistivity as an indirect correlation of root biomass;

2. a single-point MALM inversion produces a 3-D distribution of misfit values that is a measure of how likely it is that a current source (read: a root) is present at that location;

3. a multiple-point MALM inversion produces a 3-D distribution of electrical current injection into the soil, that is the most likely proxy to the hair root distribution density in the soil.

While a number of pending issues remain to be discussed and developed in future work, this step forward is substantial and paves the way for the widespread use of electrical methods and application to study root-soil interactions. This, in turn, may lead to the successful pursuit of a number of possible practical and theoretical results. Among future developments, further work needs to be conducted to establish solid links between the proposed method and the plant physiological state. A modeling study with an explicit representation of root structure in the MALM forward modeling may be done as a follow up work to understand how the proposed approach can be made more robust.

Data availability. Measured and simulated raw data, electrical imaging, and MALM data used to generate the figures can be accessed at https://doi.org/10.5281/zenodo.1464825 (Mary et al., 2018).

Author contributions. GC, YW, and SH worked on the conceptualization of the research. BM curated the data. LP, BM, and JB collected the data. BM prepared the formal analysis, designed and wrote the scripts for carrying out the simulation and inversion, and ran the obtained the results. MS and GC supervised the field work. All the authors discussed the results. BM prepared the paper with contributions from all the authors.

Competing interests. The authors declare that they have no conflict of interest.

Acknowledgements. The authors wish to acknowledge support from the projects "Water Saving in Agriculture: technological developments for the sustainable management of limited water resources in the Mediterranean area" (ERANET-MED WASA) and "Hydro-geophysical monitoring and modeling for the Earth's Critical Zone" (CPDA147114) funded by the University of Padua. In addition, the information, data or work presented herein was funded in part by the Advanced Research Projects Agency-Energy (ARPA-E), U.S. Department of Energy, under work authorization number 16/CJ000/04/08. The views and opinions of authors expressed herein do not necessarily state or reflect those of the United States Government or any agency thereof. Luca Peruzzo and Myriam Schmutz gratefully acknowledge the financial support from IDEX (Initiative D'EXellence, France), the European regional development fund Interreg Sudoe - Soil Take Care, no. SOE1/P4/F0023 - Sol Precaire.

Edited by: Marnik Vanclooster

Reviewed by: two anonymous referees 


\section{Appendix A}

\section{A1 Reciprocal measurements}

(a)

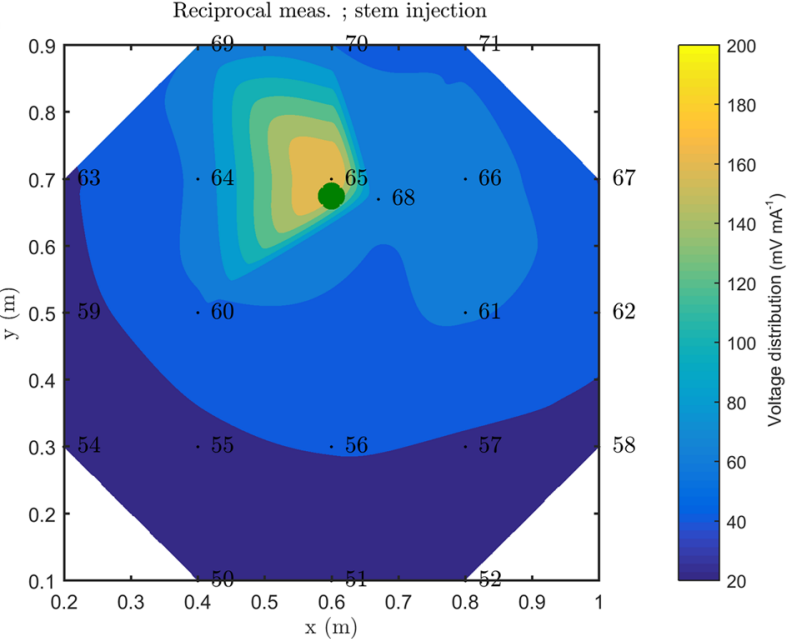

(c)

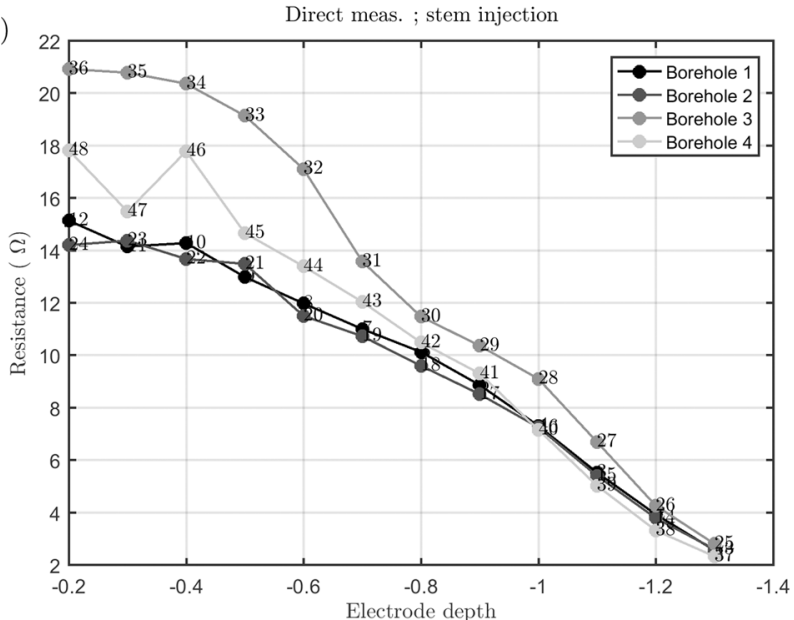

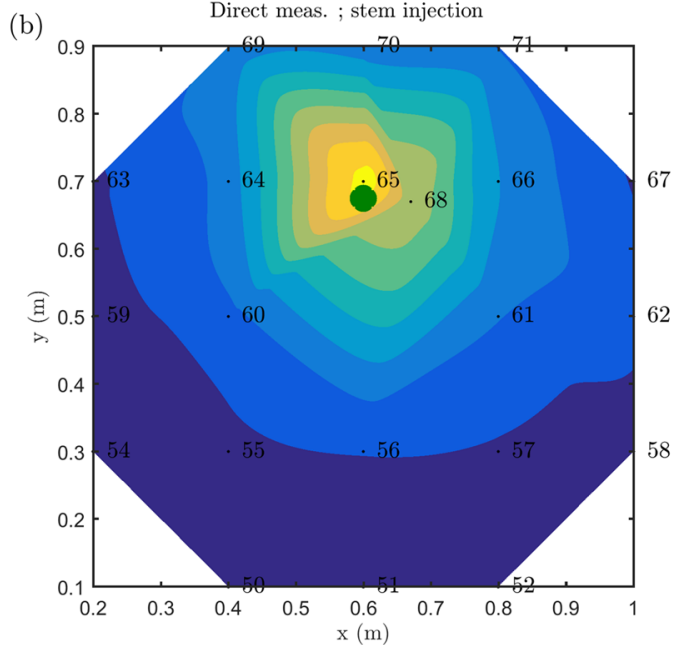

(d)

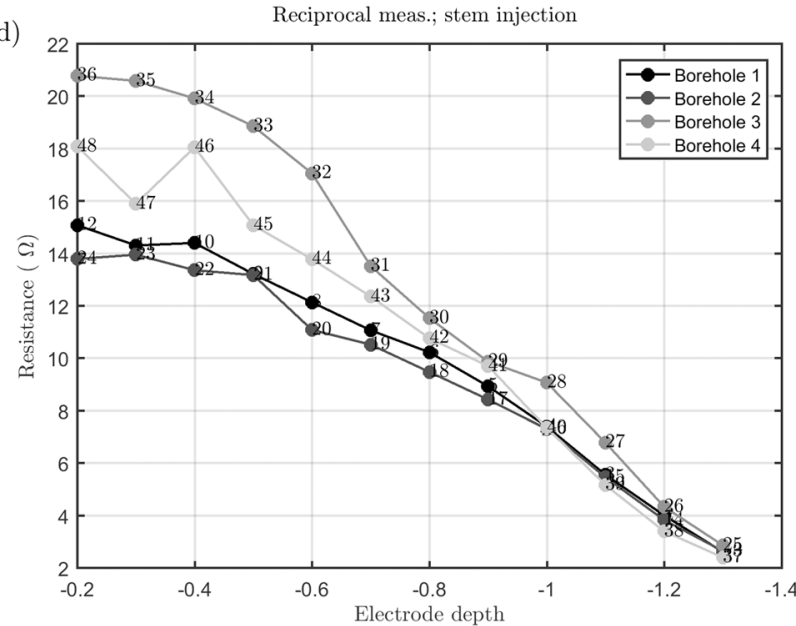

Figure A1. Spatial variations of the normalized voltage (I/U expressed in V/A) observed by surface electrodes (a, b, interpolated points) and borehole electrodes (c, $\mathbf{d})$ obtained during the MALM field measurements: direct measurements (current injected into the stem) are shown on the right, while reciprocals are shown on the left. The green dot shows the location of the plant stem $($ at $x=0.65 \mathrm{~m}, y=0.67 \mathrm{~m})$. 


\section{A2 Mesh quality check}

(a)

(b)

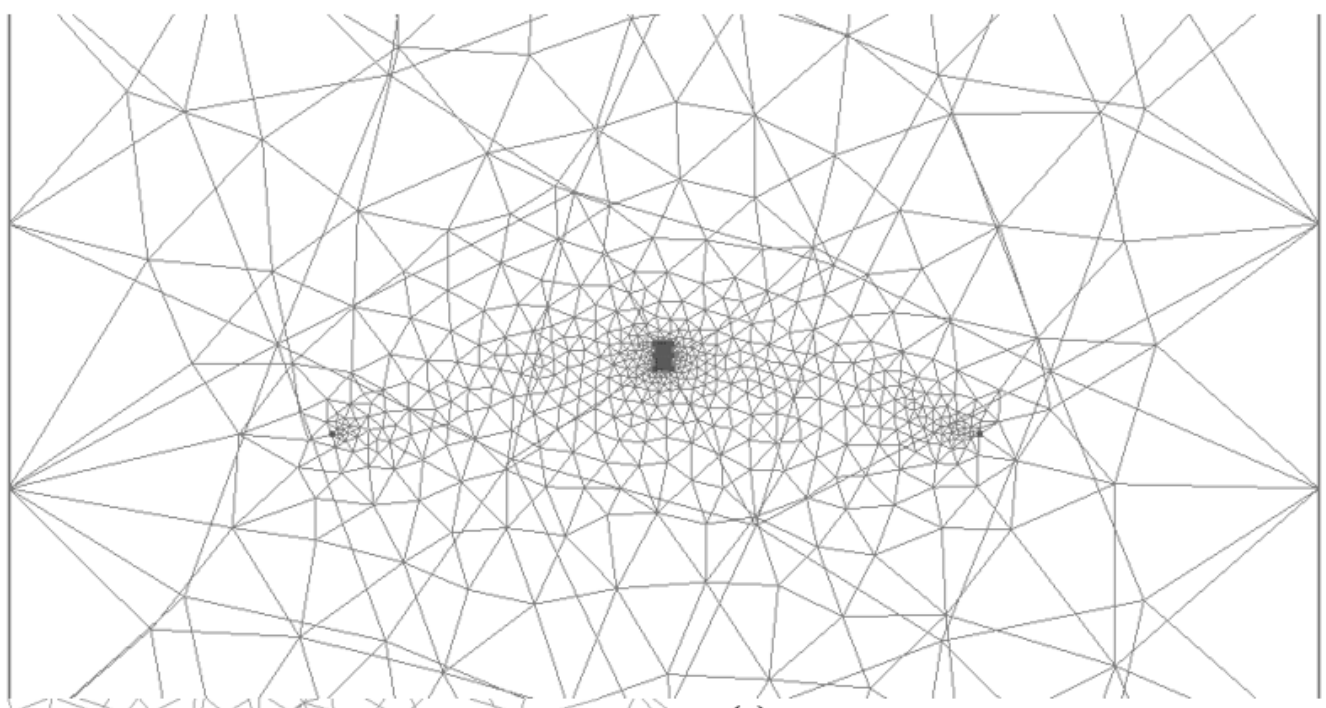

(c)
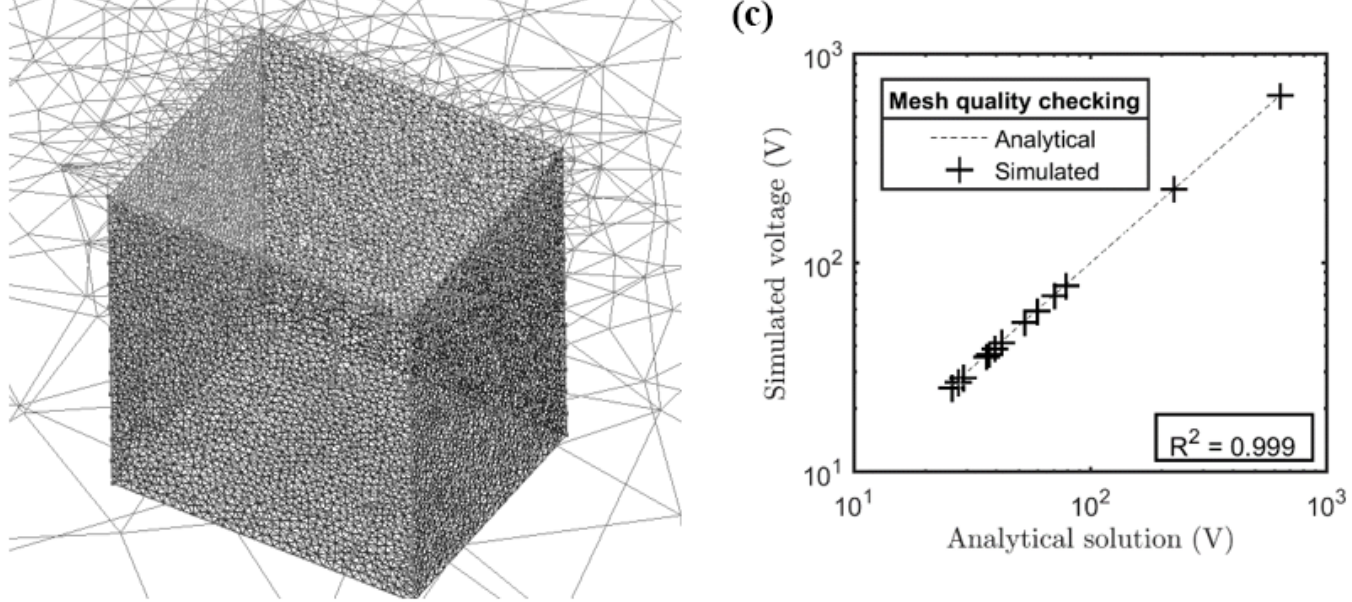

Figure A2. Plot of the finite element mesh used in this paper. (a) shows the position of remote electrodes in the mesh and position of the stem; (b) a zoomed-in image around the stem showing a mesh size approximately 5 times smaller than the electrode spacing; and (c) the plot showing the excellent correlation $(R 2=0.99)$ between numerical simulation results and the analytic solution for a homogeneous model with resistivity equal to $100 \Omega \cdot \mathrm{m}$ 


\section{References}

Amato, M., Basso, B., Celano, G., Bitella, G., Morelli, G., and Rossi, R.: In situ detection of tree root distribution and biomass by multi-electrode resistivity imaging, Tree Physiol., 28, 14411448, 2008.

Anderson, W. P. and Higinbotham, N.: Electrical Resistances of Corn Root Segments, Plant Physiol., 57, 137-141, https://doi.org/10.1104/pp.57.2.137, 1976.

André, F., van Leeuwen, C., Saussez, S., Van Durmen, R., Bogaert, P., Moghadas, D., de Rességuier, L., Delvaux, B., Vereecken, H., and Lambot, S.: High-resolution imaging of a vineyard in south of France using ground-penetrating radar, electromagnetic induction and electrical resistivity tomography, J. Appl. Geophys., 78, 113-122, https://doi.org/10.1016/j.jappgeo.2011.08.002, 2012.

Archie, G. E.: The Electrical Resistivity Log as an Aid in Determining Some Reservoir Characteristics, Trans. AIME, 146, 54-62, https://doi.org/10.2118/942054-G, 1942.

Aubrecht, L., Staněk, Z., and Koller, J.: Electrical measurement of the absorption surfaces of tree roots by the earth impedance method: 1. Theory, Tree Physiol., 26, 1105-1112, 2006.

Baize, D. and Girard, M.-C. (Eds.): Référentiel pédologique, Nouvelle éd., INRA, Paris, 1995.

Beff, L., Günther, T., Vandoorne, B., Couvreur, V., and Javaux, M.: Three-dimensional monitoring of soil water content in a maize field using Electrical Resistivity Tomography, Hydrol. Earth Syst. Sci., 17, 595-609, https://doi.org/10.5194/hess-17595-2013, 2013.

Binley, A.: R3t version 1.8, Lancaster Univ., Lancaster, UK, available at: http://www.es.lancs.ac.uk/people/amb/Freeware/ Freeware.htm., 2013.

Binley, A., Ramirez, A., and Daily, W.: Regularised image reconstruction of noisy electrical resistance tomography data, in: Process Tomography - 1995, Proceedings of the 4th Workshop of the European Concerted Action on Process Tomography, Bergen, 6-8, 1995.

Boaga, J., Rossi, M., and Cassiani, G.: Monitoring Soil-plant Interactions in an Apple Orchard Using 3-D Electrical Resistivity Tomography, Procedia Environ. Sci., 19, 394-402, https://doi.org/10.1016/j.proenv.2013.06.045, 2013.

Boaga, J., D’Alpaos, A., Cassiani, G., Marani, M., and Putti, M.: Plant-soil interactions in salt marsh environments: Experimental evidence from electrical resistivity tomography in the Venice Lagoon: plant-soil interactions in salt-marsh, Geophys. Res. Lett., 41, 6160-6166, https://doi.org/10.1002/2014GL060983, 2014.

Böhm, W.: Methods of Studying Root Systems, Springer Berlin Heidelberg, Berlin, Heidelberg, 1979.

Boleve, A.: Localisation et quantification des zones de fuites dans les digues et les barrages par la méthode du potentiel spontané, phdthesis, Université de Savoie, 24 March, available at: https://tel.archives-ouvertes.fr/tel-00381930/document (last access: 3 April 2018), 2009.

Brillante, L., Bois, B., Mathieu, O., and Lévêque, J.: Electrical imaging of soil water availability to grapevine: a benchmark experiment of several machine-learning techniques, Precis. Agric., 17, 637-658, https://doi.org/10.1007/s11119-016-9441-1, 2016.

Cassiani, G., Ursino, N., Deiana, R., Vignoli, G., Boaga, J., Rossi, M., Perri, M. T., Blaschek, M., Duttmann, R., Meyer, S., Ludwig, R., Soddu, A., Dietrich, P., and Werban, U.: Noninvasive Monitoring of Soil Static Characteristics and Dynamic States: A Case
Study Highlighting Vegetation Effects on Agricultural Land, Vadose Zone J., 11, 3, https://doi.org/10.2136/vzj2011.0195, 2012.

Cassiani, G., Boaga, J., Vanella, D., Perri, M. T., and Consoli, S.: Monitoring and modelling of soil-plant interactions: the joint use of ERT, sap flow and eddy covariance data to characterize the volume of an orange tree root zone, Hydrol. Earth Syst. Sci., 19, 2213-2225, https://doi.org/10.5194/hess-19-2213-2015, 2015.

Cassiani, G., Boaga, J., Rossi, M., Putti, M., Fadda, G., Majone, B., and Bellin, A.: Soil-plant interaction monitoring: Small scale example of an apple orchard in Trentino, North-Eastern Italy, Sci. Total Environ., 543, 851-861, https://doi.org/10.1016/j.scitotenv.2015.03.113, 2016.

Campbell, R. B., Bower, C. A., and Richards, L. A.: Change of Electrical Conductivity With Temperature and the Relation of Osmotic Pressure to Electrical Conductivity and Ion Concentration for Soil Extracts, Soil Sci. Soc. Am. J., 13, 66, https://doi.org/10.2136/sssaj1949.036159950013000C0010x, 1949.

Cermak, J., Ulrich, R., Stanek, Z., Koller, J., and Aubrecht, L.: Electrical measurement of tree root absorbing surfaces by the earth impedance method: 2. Verification based on allometric relationships and root severing experiments, Tree Physiol., 26, 11131121, https://doi.org/10.1093/treephys/26.9.1113, 2006.

Consoli, S., Stagno, F., Vanella, D., Boaga, J., Cassiani, G., and Roccuzzo, G.: Partial root-zone drying irrigation in orange orchards: Effects on water use and crop production characteristics, Eur. J. Agron., 82, 190-202, https://doi.org/10.1016/j.eja.2016.11.001, 2017.

Cuneo, I. F., Knipfer, T., Mandal, P., Brodersen, C. R., and McElrone, A. J.: Water uptake can occur through woody portions of roots and facilitates localized embolism repair in grapevine, New Phytol., 218, 506-516, https://doi.org/10.1111/nph.15032, 2018.

Daily, W., Ramirez, A., Binley, A., and LeBrecque, D.: Electrical resistance tomography, Lead. Edge, 23, 438-442, https://doi.org/10.1190/1.1729225, 2004.

Dalton, F. N.: In-situ root extent measurements by electrical capacitance methods, Plant Soil, 173, 157-165, https://doi.org/10.1007/BF00155527, 1995.

De Carlo, L., Perri, M. T., Caputo, M. C., Deiana, R., Vurro, M., and Cassiani, G.: Characterization of a dismissed landfill via electrical resistivity tomography and mise-à-la-masse method, J. Appl. Geopys., 98, 1-10, doi:10.1016/j.jappgeo.2013.07.010, 2013.

Dittmer, H. J.: A Quantitative Study of the Roots and Root Hairs of a Winter Rye Plant (Secale Cereale), Am. J. Bot., 24, 417-420, https://doi.org/10.2307/2436424, 1937.

Garré, S., Javaux, M., Vanderborght, J., Pagès, L., and Vereecken, H.: Three-Dimensional Electrical Resistivity Tomography to Monitor Root Zone Water Dynamics, Vadose Zone J., 10, 412424, https://doi.org/10.2136/vzj2010.0079, 2011.

Gerós, H., Chaves, M. M., Gil, H. M., and Delrot, S.: Grapevine in a Changing Environment: A Molecular and Ecophysiological Perspective, John Wiley \& Sons, 2015.

Gibert, D., Le Mouël, J.-L., Lambs, L., Nicollin, F., and Perrier, F.: Sap flow and daily electric potential variations in a tree trunk, Plant Sci., 171, 572-584, https://doi.org/10.1016/j.plantsci.2006.06.012, 2006.

Gora, E. M. and Yanoviak, S. P.: Electrical properties of temperate forest trees: a review and quantitative comparison with vines, 
Can. J. Forest Res., 45, 236-245, https://doi.org/10.1139/cjfr2014-0380, 2015.

Gora, E. M., Bitzer, P. M., Burchfield, J. C., Schnitzer, S. A., and Yanoviak, S. P.: Effects of lightning on trees: A predictive model based on in situ electrical resistivity, Ecol. Evol., 7, 8523-8534, https://doi.org/10.1002/ece3.3347, 2017.

Grote, K., Anger, C., Kelly, B., Hubbard, S., and Rubin, Y.: Characterization of soil water content variability and soil texture using GPR groundwave techniques, J. Environ. Eng. Geoph., 15, 93$110,2010$.

Hagrey, S.: Geophysical imaging of root-zone, trunk, and moisture heterogeneity, J. Exp. Bot., 58, 839-854, https://doi.org/10.1093/jxb/erl237, 2007.

Herralde, F. de, Savé, R., Aranda, X., and Biel, C.: Grapevine Roots and Soil Environment: Growth, Distribution and Function, in: Methodologies and Results in Grapevine Research, 120, Springer, Dordrecht, 2010.

Judd, L., Jackson, B., and Fonteno, W.: Advancements in Root Growth Measurement Technologies and Observation Capabilities for Container-Grown Plants, Plants, 4, 369-392, https://doi.org/10.3390/plants4030369, 2015.

Le Mouël, J.-L., Gibert, D., and Poirier, J.-P.: On transient electric potential variations in a standing tree and atmospheric electricity, C. R. Geosci., 342, 95-99, https://doi.org/10.1016/j.crte.2009.12.001, 2010.

Manoli, G., Rossi, M., Pasetto, D., Deiana, R., Ferraris, S., Cassiani, G., and Putti, M.: An iterative particle filter approach for coupled hydro-geophysical inversion of a controlled infiltration experiment, J. Comput. Phys., 283, 37-51, https://doi.org/10.1016/j.jcp.2014.11.035, 2015.

Martin, T.: Complex resistivity measurements on oak, Eur. J. Wood Wood Prod., 70, 45-53, https://doi.org/10.1007/s00107010-0493-z, 2012.

Martin, T. and Günther, T.: Complex resistivity tomography (CRT) for fungus detection on standing oak trees, Eur. J. Forest Res., 132, 765-776, https://doi.org/10.1007/s10342-013-0711-4, 2013.

Mary, B., Saracco, G., Peyras, L., Vennetier, M., Mériaux, P., and Camerlynck, C.: Mapping tree root system in dikes using induced polarization: Focus on the influence of soil water content, J. Appl. Geophys., 135, 387-396, https://doi.org/10.1016/j.jappgeo.2016.05.005, 2016.

Mary, B., Abdulsamad, F., Saracco, G., Peyras, L., Vennetier, M., Mériaux, P., and Camerlynck, C.: Improvement of coarse root detection using time and frequency induced polarization: from laboratory to field experiments, Plant Soil, https://doi.org/10.1007/s11104-017-3255-4, 2017.

Mary, B., Peruzzo, L., Boaga, J., Schmutz, M., Wu, Y., Hubbard, S. S., and Cassiani, G: Data and results for manuscript "Small scale characterization of vine plant root water uptake via 3-D electrical resistivity tomography and mise-à-la-masse method", Data set, Zenodo, https://doi.org/10.5281/zenodo.1464825, 2018.

Maxwell, R. M., Chow, F. K., and Kollet, S. J.: The groundwater-land-surface-atmosphere connection: Soil moisture effects on the atmospheric boundary layer in fullycoupled simulations, Adv. Water Resour., 30, 2447-2466, https://doi.org/10.1016/j.advwatres.2007.05.018, 2007.

Michot, D., Benderitter, Y., Dorigny, A., Nicoullaud, B., King, D., and Tabbagh, A.: Spatial and temporal moni- toring of soil water content with an irrigated corn crop cover using surface electrical resistivity tomography: soil water study using electrical resistivity, Water Resour. Res., 39, https://doi.org/10.1029/2002WR001581, 2003.

Monk, C.: Ecological Importance of Root/Shoot Ratios, B. Torrey Bot. Club, 93, 402-406, https://doi.org/10.2307/2483412, 1966.

Morano, L. and Kliewer, W. M.: Root Distribution of Three Grapevine Rootstocks Grafted to Cabernet Sauvignon Grown on a Very Gravelly Clay Loam Soil in Oakville, California, Am. J. Enol. Vitic., 45, 345-348, 1994.

Morlat, R. and Jacquet, A.: Grapevine Root System and Soil Characteristics in a Vineyard Maintained Long-term with or without Interrow Sward, Am. J. Enol. Vitic., 54, 1-7, 2003.

Nagarajah, S.: Effects of Soil Texture on the Rooting Patterns of Thompson Seedless Vines on Own Roots and on Ramsey Rootstock in Irrigated Vineyards, Am. J. Enol. Vitic., 38, 54-59, 1987.

Ozier-Lafontaine, H. and Bajazet, T.: Analysis of Root Growth by Impedance Spectroscopy (EIS), Plant Soil, 277, 299-313, https://doi.org/10.1007/s11104-005-7531-3, 2005.

Parasnis, D.: Reciprocity theorems in geoelectric and geoelectromagnetic work, Geoexploration, 25, 177-198, 1988.

Parasnis, D. S.: Three-dimensional electric mise-a-la-masse survey of an irregular lead-zinc-copper deposit in central sweden, Geophys. Prospect., 15, 407-437, https://doi.org/10.1111/j.13652478.1967.tb01796.x, 1967.

Perri, M. T., De Vita, P., Masciale, R., Portoghese, I., Chirico, G. B., and Cassiani, G.: Time-lapse Mise-à-laMasse measurements and modeling for tracer test monitoring in a shallow aquifer, J. Hydrol., 561, 461-477, https://doi.org/10.1016/j.jhydrol.2017.11.013, 2018.

Philip, J. R.: Plant Water Relations: Some Physical Aspects, Annu. Rev. Plant Phys., 17, 245-268, https://doi.org/10.1146/annurev.pp.17.060166.001333, 1966.

Postic, F. and Doussan, C.: Benchmarking electrical methods for rapid estimation of root biomass, Plant Methods, 12, https://doi.org/10.1186/s13007-016-0133-7, 2016.

Pyatygin, S. S., Opritov, V. A., and Vodeneev, V. A.: Signaling role of action potential in higher plants, Russ. J. Plant Physiol., 55, 285-291, https://doi.org/10.1134/S1021443708020179, 2008.

Rao, S., Meunier, F., Ehosioke, S., Lesparre, N., Kemna, A., Nguyen, F., Garré, S., and Javaux, M.: A mechanistic model for electrical conduction in soil-root continuum: a virtual rhizotron study, Biogeosciences Discuss., https://doi.org/10.5194/bg-2018-280, in review, 2018.

Rhoades, J. D., Raats, P. A. C., and Prather, R. J.: Effects of Liquid-phase Electrical Conductivity, Water Content, and Surface Conductivity on Bulk Soil Electrical Conductivity1, Soil Sci. Soc. Am. J., 40, 651, https://doi.org/10.2136/sssaj1976.03615995004000050017x, 1976.

Robain, H., Albouy, Y., Dabas, M., Descloitres, M., Camerlynck, C., Mechler, P., and Tabbagh, A.: The location of infinite electrodes in pole-pole electrical surveys: consequences for 2-D imaging, J. Appl. Geophys., 41, 313-333, 1999.

Rossi, M., Manoli, G., Pasetto, D., Deiana, R., Ferraris, S., Strobbia, C., Putti, M., and Cassiani, G.: Coupled inverse modeling of a controlled irrigation experiment using multiple hydro-geophysical data, Adv. Water Resour., 82, 150-165, https://doi.org/10.1016/j.advwatres.2015.03.008, 2015. 
Saracco, G., Labazuy, P., and Moreau, F.: Localization of selfpotential sources in volcano-electric effect with complex continuous wavelet transform and electrical tomography methods for an active volcano, Geophys. Res. Lett., 31, L12610, https://doi.org/10.1029/2004GL019554, 2004.

Schlumberger, C.: Etude sur la prospection electrique du sous-sol, Gauthier-Villars, 1920.

Stokes, A., Fourcaud, T., Hruska, J., Cermak, J., Nadyezdhina, N., Nadyezhdin, V., and Praus, L.: An evaluation of different methods to investigate root system architecture of urban trees in situ: I. Ground-penetrating radar, Journal of Arboriculture, 28, 2-10, 2002

Srayeddin, I. and Doussan, C.: Estimation of the spatial variability of root water uptake of maize and sorghum at the field scale by electrical resistivity tomography, Plant and Soil, 319, 185-207, https://doi.org/10.1007/s11104-008-9860-5, 2009.

Stevens, R. and Douglas, T.: Distribution of grapevine roots and salt under drip and full-ground cover microjet irrigation systems, Irrigation Sci., 15, 147-152, https://doi.org/10.1007/BF00193681, 1994.

Swanepoel, J. and Southey, J.: The influence of rootstocks on the rooting pattern of the grapevine, S. Afr. J. Enol. Vitic., 10, 2328, 1989.

Taylor, H. M., Upchurch, D. R., and McMichael, B. L.: Applications and limitations of rhizotrons and minirhizotrons for root studies, Plant and Soil, 129, 29-35, https://doi.org/10.1007/BF00011688, 1990.

Tomasi, D., Battista, F., Gaiotti, F., Mosetti, D., and Bragato, G.: Influence of Soil on Root Distribution: Implications for Quality of Tocai Friulano Berries and Wine, Am. J. Enol. Viticult., 66, 363-372, https://doi.org/10.5344/ajev.2015.14077, 2015.
Vanella, D., Cassiani, G., Busato, L., Boaga, J., Barbagallo, S., Binley, A., and Consoli, S.: Use of small scale electrical resistivity tomography to identify soil-root interactions during deficit irrigation, J. Hydrol., 556, 310-324, https://doi.org/10.1016/j.jhydrol.2017.11.025, 2018.

Waxman, M. H. and Smits, L. J. M.: Electrical Conductivities in Oil-Bearing Shaly Sands, Soc. Petrol. Eng. J., 8, 107-122, https://doi.org/10.2118/1863-A, 1968.

Weigand, M. and Kemna, A.: Multi-frequency electrical impedance tomography as a non-invasive tool to characterize and monitor crop root systems, Biogeosciences, 14, 921-939, https://doi.org/10.5194/bg-14-921-2017, 2017.

Weller, A., Nordsiek, S., and Bauerochse, A.: Spectral Induced Polarisation - a Geophysical Method for Archaeological Prospection in Peatlands, J. Wetl. Archaeol., 6, 105-125, https://doi.org/10.1179/jwa.2006.6.1.105, 2006.

Werban, U., Attia al Hagrey, S., and Rabbel, W.: Monitoring of root-zone water content in the laboratory by 2-D geoelectrical tomography, J. Plant Nutr. Soil Sc., 171, 927-935, https://doi.org/10.1002/jpln.200700145, 2008.

York, L. M., Carminati, A., Mooney, S. J., Ritz, K., and Bennett, M. J.: The holistic rhizosphere: integrating zones, processes, and semantics in the soil influenced by roots, J. Exp. Bot., 67, 36293643, https://doi.org/10.1093/jxb/erw108, 2016.

Zanetti, C., Weller, A., Vennetier, M., and Mériaux, P.: Detection of buried tree root samples by using geoelectrical measurements: a laboratory experiment, Plant Soil, 339, 273-283, https://doi.org/10.1007/s11104-010-0574-0, 2011. 